\title{
The Endophytic Pseudomonas sp. S57 for Plant-Growth Promotion and the Biocontrol of Phytopathogenic Fungi and Nematodes
}

\author{
Patricio Muñoz Torres 1,2,*, Steffany Cárdenas 1,2, Mabel Arismendi Macuer 1,2, Nelly Huanacuni 1,2, \\ Wilson Huanca-Mamani ${ }^{1}$, Denise Cifuentes ${ }^{2}$ and Germán F. Sepúlveda Chavera ${ }^{1, *}$ \\ 1 Laboratorio de Patología Vegetal y Bioproductos, Facultad de Ciencias Agronómicas, Universidad de \\ Tarapacá, Av. General Velásquez 1775, Arica 1000000, Chile; sfcninasivincha@gmail.com (S.C.); \\ arismendimabel@gmail.com (M.A.M.); nelly.huanacuni@gmail.com (N.H.); whuanca@uta.cl (W.H.-M.) \\ 2 University of California Davis Chile Life Sciences Innovation Center, Av. Santa María 2670, \\ Santiago 7520424, Chile; dcifuentes@ucdavis.edu \\ * $\quad$ Correspondence: pmunozt@uta.cl (P.M.T.); gsepulve@uta.cl (G.F.S.C.); Tel.: +56-58-2386104 (G.F.S.C.)
}

check for updates

Citation: Muñoz Torres, P.; Cárdenas, S.; Arismendi Macuer, M.; Huanacuni, N.; Huanca-Mamani, W.; Cifuentes, D.; Sepúlveda Chavera, G.F. The Endophytic Pseudomonas sp. S57 for Plant-Growth Promotion and the Biocontrol of Phytopathogenic Fungi and Nematodes. Plants 2021, 10, 1531. https://doi.org/10.3390/plants1008 1531

Academic Editors: Giovanna Visioli, Agnieszka Jamiołkowska, Izabela Kot and Francesca Degola

Received: 30 June 2021

Accepted: 19 July 2021

Published: 27 July 2021

Publisher's Note: MDPI stays neutral with regard to jurisdictional claims in published maps and institutional affiliations.

Copyright: (c) 2021 by the authors. Licensee MDPI, Basel, Switzerland. This article is an open access article distributed under the terms and conditions of the Creative Commons Attribution (CC BY) license (https:/ / creativecommons.org/licenses/by/ $4.0 /)$.

\begin{abstract}
Oregano from Socoroma (Atacama Desert) is characterized by its unique organoleptic properties and distinctive flavor and it is produced using ancestral pesticide-free agricultural practices performed by the Aymara communities. The cultivation in this zone is carried out under extreme conditions where the standard production of different crops is limited by several environmental factors, including aridity, high concentration of salts, and boron among others. However, oregano plants are associated with microorganisms that mitigate biotic and abiotic stresses present in this site. In this work, the S57 strain (member of the Pseudomonas genus that is closely related to Pseudomonas lini) was isolated from roots of oregano plants, which are grown in soils with high content of nonsodium salts and aluminum. This bacterium stimulates the growth of Micro-Tom tomato plants irrigated with saline-boric water. Moreover, it controls the growth of phytopathogenic fungi Fusarium oxysporum and Botrytis cinerea and the nematode Meloidogyne incognita under saline-boric conditions. Together with the high levels of bacterial biomass $(\sim 47 \mathrm{~g} / \mathrm{L})$, these results allow the establishment of the bases for developing a potential new agricultural bioproduct useful for arid and semiarid environments where commercial biological products show erratic behavior.
\end{abstract}

Keywords: Atacama Desert; endophyte; plant-growth promoting bacteria; biocontrol; preAndean agriculture

\section{Introduction}

Socoroma (in Aymara Chukuruma; running water) Valley $\left(18^{\circ} 15^{\prime} 37^{\prime \prime} \mathrm{S}, 69^{\circ} 36^{\prime} 24^{\prime \prime} \mathrm{W}\right)$ is located at the Andean pre-mountain range of the Arica and the Parinacota Region at 3070 m.a.s.l. in the Commune of Putre in the extreme north of the Atacama Desert, Chile [1]. This valley is characterized by the cultivation of oregano [2], which possesses unique organoleptic properties, possesses geographical indication distinction and granted the seal of origin by the National Institute of Intellectual Property, INAPI, Chile [3]. Particularly, oregano cultivation is performed under ancestral agricultural practices, in which crops are maintained employing pesticide-free applications, harboring unexplored microbial genetics resources associated with this type of plants. Microbial communities associated to plant tissues (plant microbiome) are considered beneficial because they contribute to the plant by mitigating biotic and abiotic stress conditions [4,5]. Thus, this allow plants to survive under the extreme conditions that prevail in this region, including aridity, high concentrations of salts and boron, a wide thermal amplitude between the day and night, poor soil composition, and high UV radiation among other extreme environmental conditions which are restrictive for agricultural activities in arid and semiarid regions [6,7]. 
Under the extreme conditions of this zone, plant-associated bacteria play a crucial role in maintaining the proper functioning of plants [8]. These bacteria are known as plant-growth-promoting rhizobacteria (PGPR) and correspond to a free-living soil bacteria with the ability to colonize the rhizosphere and roots, which promotes the growth through the release of metabolites that act directly in plants [9] including the production of phytohormones, such as indole-3-acetic acid (IAA), gibberelins, and cytokinins [10,11]; and the fixation of elemental nitrogen [12]. Furthermore, the solubilization of minerals also occur, such as inorganic phosphate and iron $[13,14]$, and the biological control of phytopathogenic organisms through the production of inhibitory compounds and hydrolytic enzymes also occur [15].

Beneficial PGPR associated with oregano plants from Socoroma could increase interest due to the extreme conditions where they are cultivated. Under this type of conditions, bacteria could confer tolerance to the different stresses to which oregano crops are naturally subjected to, which allows plant survival [11]. Although different bacteria have been isolated from several plants [16], PGPR associated with oregano from Socoroma have been scarcely described and harbors a high potential to characterize the plant-microorganism interaction under extreme conditions of cultivation, to describe adaptation mechanisms to this kind of environment, and to exploit new natural compounds for biotechnological and agricultural purposes. This study was focused on the isolation, identification, and in vitro and in planta functional characterization of the Pseudomonas sp. strain S57, which was obtained from oregano roots from Socoroma. The S57 isolate was selected from the plantassociated bacterial culture collection of the Laboratory of Plant Pathology and Bioproducts (Universidad de Tarapacá, Chile) because it possesses promissory plant-growth promoting activities making it an excellent candidate for the development of a new bioproduct. This strain is closely related to Pseudomonas lini and qualitative functional analysis revealed that this bacterium possesses plant-growth-promoting activities and a wide range of antifungal properties against several phytopathogenic fungi, including under saline-boric conditions. Furthermore, bacterial cultures were optimized in a flask and bioreactor to produce high quantities of biomass to perform the experimental procedure in Micro-Tom tomato plants and not only to establish the baseline for the development of a new bioproduct tolerant relative to the extreme conditions present in the valley of Arica and Parinacota Region, Chile, but also relative to arid and semiarid environments.

\section{Results}

\subsection{Soil Samples Characterization}

Three samples were taken from different sites in Socoroma to characterize arable soils and to establish the extreme conditions where oregano plants are cultivated (Table 1). The S1 sample showed high levels of total nitrogen, phosphorous, potassium, boron, aluminum, and copper and accepted values of sulfur and sodium were found. For the S2 sample, excessive levels of total nitrogen, phosphorous, potassium, sulfur, aluminum, and copper were detected. Meanwhile, boron and sodium levels were in accepted values. S3 sample showed high levels of potassium and aluminum; deficient levels of total nitrogen, sulfur, and boron; and accepted values for phosphorous, copper, and sodium. The NPKS content in the three samples showed a direct relationship with the organic matter content. All the samples showed high electrical conductivity, suggesting non-sodium highly saline soils due to the low concentration of sodium. Measured $\mathrm{pH}$ values indicated the presence of strong acid soils for S1 and S2 samples and slightly acid soil for S3.

Pesticide residues analysis (not showed) included the detection of 163 insecticides, acaricides, and nematicides; 74 herbicides and plant growth regulators; and 93 fungicides. No pesticide residues were detected in the three samples, which confirms free-pesticides agricultural practices. 
Table 1. Composition of soil samples from Socoroma.

\begin{tabular}{|c|c|c|c|}
\hline Parameter & S1 & S2 & S3 \\
\hline GPS Location & $\begin{array}{l}18^{\circ} 15^{\prime} 13.3^{\prime \prime} \mathrm{S} \\
69^{\circ} 36^{\prime} 36.0^{\prime \prime} \mathrm{W}\end{array}$ & $\begin{array}{l}18^{\circ} 15^{\prime} 14.8^{\prime \prime} S \\
69^{\circ} 36^{\prime} 46.3^{\prime \prime} W\end{array}$ & $\begin{array}{c}18^{\circ} 15^{\prime} 50.1^{\prime \prime} \mathrm{S} \\
69^{\circ} 35^{\prime \circ} 39.0^{\prime \prime} \mathrm{W}\end{array}$ \\
\hline Altitude (m.a.s.l) & 2909 & 2892 & 3090 \\
\hline Total N (\%) & 0.37 & 0.20 & 0.07 \\
\hline $\mathrm{P}(\mathrm{mg} / \mathrm{kg})$ & 77.30 & 57.00 & 21.49 \\
\hline $\mathrm{K}(\mathrm{mg} / \mathrm{kg})$ & 0.85 & 0.79 & 0.77 \\
\hline $\mathrm{S}(\mathrm{mg} / \mathrm{kg})$ & 24.00 & 44.50 & 16.00 \\
\hline $\mathrm{B}(\mathrm{mg} / \mathrm{kg})$ & 13.00 & 0.68 & 0.04 \\
\hline $\mathrm{Al}(\mathrm{cmol} / \mathrm{kg})$ & 11.90 & 5.12 & 0.12 \\
\hline $\mathrm{Cu}(\mathrm{mg} / \mathrm{kg})$ & 4.11 & 3.70 & 0.80 \\
\hline $\mathrm{Na}(\mathrm{cmol} / \mathrm{kg})$ & 0.28 & 0.33 & 0.30 \\
\hline $\mathrm{pH}$ & 4,66 & 4.75 & 6.11 \\
\hline Organic matter $(\%)$ & 4.87 & 2.58 & 0.79 \\
\hline $\begin{array}{c}\text { Electrical } \\
\text { conductivity }(\mathrm{dS} / \mathrm{cm})\end{array}$ & 87.6 & 116.2 & 102.2 \\
\hline
\end{tabular}

\subsection{S57 Strain Characterization and Identification}

The S57 strain was isolated as an endophytic bacterium from roots of oregano plants from Socoroma. Microbiological characterization (Table 2) showed Gram negative straight rod cells, which are motile in semi-solid media and able to produce gas after the addition of $3 \% \mathrm{H}_{2} \mathrm{O}_{2}$, which indicates the production of catalase enzyme. The colonies were yellowish, circular, and convex with regular margins after 2 days of growth on King's medium B agar. This bacterium produced acids from D-mannitol, D-glucose, D-fructose, D-galactose, D-rhamnose, D-melibiose, sucrose, and lactose, but no acid production was detected when D-sorbitol and D-cellobiose were used as carbon sources.

Table 2. Microbiological characterization of the S57 strain. A positive reaction is indicated as +; meanwhile, no reaction is indicated as -.

\begin{tabular}{cc}
\hline Parameter & S57 \\
\hline Gram staining & - \\
\hline Morphology & Straight rods \\
\hline Motility test & + \\
\hline Catalase & - \\
\hline Acid production from: & + \\
D-Sorbitol & + \\
D-Mannitol & + \\
D-Glucose & + \\
D-Fructose & + \\
D-Galactose & + \\
D-Rhamnose & - \\
D-Melibiose & + \\
D-Cellobiose & + \\
Sucrose & + \\
Lactose & +
\end{tabular}

Antibiotic susceptibility of the S57 strain was performed by the disk diffusion method (Table 3), observing that this bacterium was sensitive to chloramphenicol (50 $\mu \mathrm{g})$, ciprofloxacin (1 and $10 \mu \mathrm{g})$, and kanamycin $(30 \mu \mathrm{g})$. S57 showed intermediate resistance to chloram- 
phenicol $(10 \mu \mathrm{g})$, kanamycin $(5 \mu \mathrm{g})$, and neomycin (10 and $30 \mu \mathrm{g})$. Differences in the susceptibility using chloramphenicol and kanamycin could be explained by a lesser diffusion of the antibiotic subjected to compound concentration. Moreover, this strain was resistant to amoxycillin, ampicillin, and penicillin $\mathrm{G}$, which is expected due to $\beta$-lactam antibiotics being mainly active against Gram positive bacteria.

Table 3. Antibiotic susceptibility test of the S57 strain. Two antibiotic quantities were employed to determine differences in the behavior of S57 bacterium in the susceptibility test. Error corresponds to the standard deviation of the independent assays.

\begin{tabular}{cccc}
\hline Antibiotic & Quantity & Inhibition Diameter (cm) & Susceptibility \\
\hline Amoxicillin & $2 \mu \mathrm{g}$ & 0.0 & Resistant \\
& $25 \mu \mathrm{g}$ & 0.0 & Resistant \\
\hline Ampicillin & $2 \mu \mathrm{g}$ & 0.0 & Resistant \\
& $25 \mu \mathrm{g}$ & 0.0 & Resistant \\
\hline Chloramphenicol & $10 \mu \mathrm{g}$ & $12.3 \pm 0.4$ & Intermediate \\
& $50 \mu \mathrm{g}$ & $24.3 \pm 1.0$ & Sensitive \\
\hline Ciprofloxacin & $1 \mu \mathrm{g}$ & $32.0 \pm 0.5$ & Sensitive \\
& $10 \mu \mathrm{g}$ & $40.7 \pm 0.3$ & Sensitive \\
\hline Kanamycin & $5 \mu \mathrm{g}$ & $15.0 \pm 1.0$ & Intermediate \\
& $30 \mu \mathrm{g}$ & $22.3 \pm 0.4$ & Sensitive \\
\hline Neomycin & $10 \mu \mathrm{g}$ & $10.3 \pm 0.4$ & Intermediate \\
& $30 \mu \mathrm{g}$ & $14.0 \pm 0.0$ & Intermediate \\
\hline Penicillin G & $1 \mathrm{U}$ & 0.0 & Resistant \\
& $10 \mathrm{U}$ & 0.0 & Resistant \\
\hline
\end{tabular}

Sequencing and comparison of 16S rRNA gene to sequences deposited in GenBank revealed that the S57 strain is a member of Pseudomonas genus and the phylogenetic analysis using the Neighbor-Joining method (Figure 1) showed the S57 strain was closely related to the PGPR Pseudomonas lini.

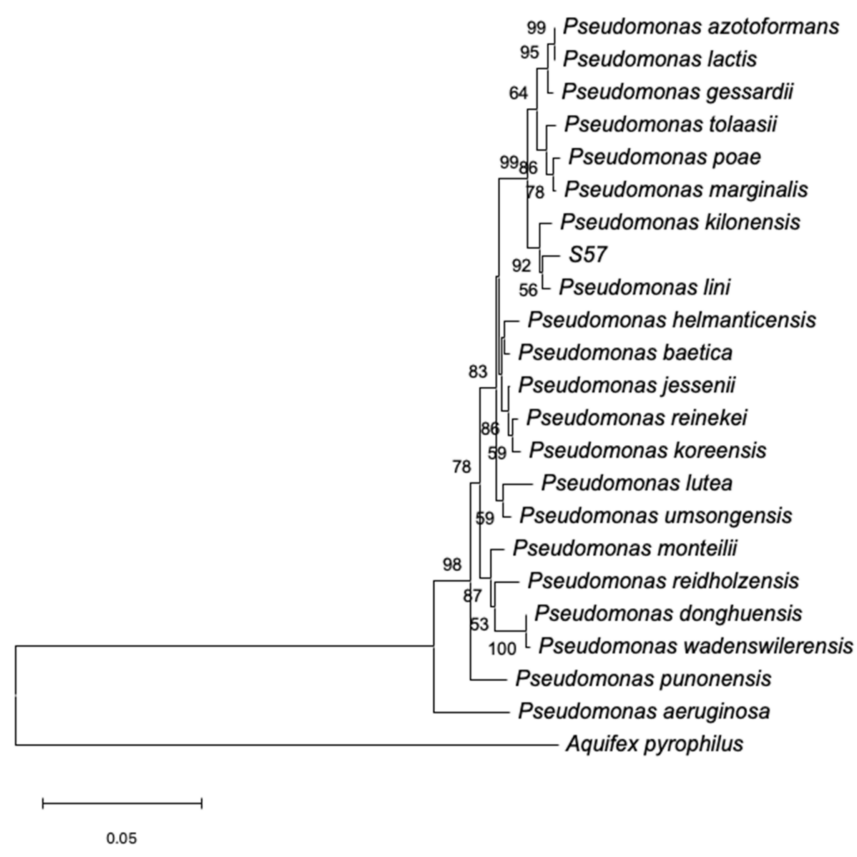

Figure 1. Neighbor-joining tree of the partial 16S rRNA gene sequence of the S57 strain and the closely related species of Pseudomonas genus. 


\subsection{Tolerance to $\mathrm{NaCl}$ and $\mathrm{H}_{3} \mathrm{BO}_{3}$ of the $\mathrm{S} 57$ Strain}

A qualitative methodology was performed to determine the tolerance of the S57 strain to saline-boric conditions (Table 4). Abundant growth was observed in King's medium B supplemented with $8 \mathrm{~g} / \mathrm{L}$ and $15 \mathrm{~g} / \mathrm{L}$ of $\mathrm{NaCl}$ or $10-100 \mathrm{ppm}$ of $\mathrm{H}_{3} \mathrm{BO}_{3}$ similar to the control conditions in the absence of $\mathrm{NaCl}$ and $\mathrm{H}_{3} \mathrm{BO}_{3}$. However, poor growth was detected when $20 \mathrm{~g} / \mathrm{L} \mathrm{NaCl}$ was added to the medium. When the liquid medium was supplement with $0.86 \mathrm{~g} / \mathrm{L} \mathrm{NaCl}$ and $114 \mathrm{ppm}$ of $\mathrm{H}_{3} \mathrm{BO}_{3}$ (1× Lluta irrigation water), abundant growth of the S57 strain was detected. Furthermore, poor growth was observed using $9 \times$ Lluta irrigation water and no growth was perceived using higher concentrations of the $\mathrm{NaCl}-$ $\mathrm{H}_{3} \mathrm{BO}_{3}$ mixture.

Table 4. Tolerance of the $\mathrm{S} 57$ strain to $\mathrm{NaCl}$ and $\mathrm{H}_{3} \mathrm{BO}_{3}$. Bacterial growth was registered as ++: abundant growth, similar to control condition, and in the absence of $\mathrm{NaCl}$ and $\mathrm{H}_{3} \mathrm{BO}_{3}$; + : poor growth; and -: no growth.

\begin{tabular}{cc}
\hline Condition & Bacterial Growth \\
\hline Control & ++ \\
\hline $8 \mathrm{~g} / \mathrm{L} \mathrm{NaCl}$ & ++ \\
\hline $15 \mathrm{~g} / \mathrm{L} \mathrm{NaCl}$ & ++ \\
\hline $20 \mathrm{~g} / \mathrm{L} \mathrm{NaCl}^{-}$ & + \\
\hline $10 \mathrm{ppm} \mathrm{H} \mathrm{BO}_{3}$ & ++ \\
\hline $50 \mathrm{ppm} \mathrm{H}_{3} \mathrm{BO}_{3}$ & ++ \\
\hline $100 \mathrm{ppm} \mathrm{H}_{3} \mathrm{BO}_{3}$ & ++ \\
\hline $1 \times$ Lluta irrigation water & + \\
\hline $9 \times$ Lluta irrigation water & - \\
\hline $10 \times$ Lluta irrigation water & ++
\end{tabular}

\subsection{In Vitro PGP Traits and Antifungal Activity of the S57 Strain}

In vitro PGP activities of the S57 strain are described in Table 5. S57 bacterium grew in $\mathrm{NFb}$ semisolid medium and formed a subsurface veil-like pellicle indicating the bacterial ability to fix elemental nitrogen. Furthermore, the S57 strain was capable of solubilizing phosphate in PVK solid medium as it was observed through the apparition of a clear halo rounding the colony. After 5 days of inoculation in fresh King's medium B, the S57 isolate was able to produce $7.9 \mu \mathrm{g} / \mathrm{mL}$ of IAA and $24.2 \mathrm{psu}$ of siderophores.

Table 5. In vitro PGP traits of the S57 strain. A positive reaction is indicated as + . Error corresponds to standard deviation of the independent assays.

\begin{tabular}{cc}
\hline PGP Trait & Result \\
\hline Nitrogen fixation & + \\
Phosphate solubilization & + \\
(IAA) $(\mu \mathrm{g} / \mathrm{mL})$ & $7.9 \pm 0.5$ \\
Siderophore production $(\mathrm{psu})$ & $24.2 \pm 3.16$ \\
\hline
\end{tabular}

The antifungal activity of the S57 strain is shown in Table 6. Under standard conditions (absence of $\mathrm{NaCl}$ and $\mathrm{H}_{3} \mathrm{BO}_{3}$ ), S57 isolate showed antifungal activity against the phytopathogens Fusarium oxysporum (23.5\%), Botrytis cinerea (48.3\%), Geotrichum candidum $(58.6 \%)$, and Monilinia fructicola $(67.2 \%)$, reaching IMRG percentages $\geq 50 \%$ for the last three fungi. When $10 \mathrm{~g} / \mathrm{L} \mathrm{NaCl}$ and $110 \mathrm{ppm} \mathrm{H}_{3} \mathrm{BO}_{3}$ were added to the culture medium (saline-boric conditions), antifungal activities against $F$. oxysporum and B. cinerea were unaltered; meanwhile, the ability to control G. candidum and M. fructicola decreased to $29.6 \%$ and $52.3 \%$, respectively. Due to F. oxysporum and B. cinerea being the most common 
phytopathogenic fungi present in the Arica and Parinacota Region, a dual culture assay using irrigation water from the Lluta River instead of distilled water was performed and observed that the use of Lluta irrigation water did not affect the antifungal activity against these phytopathogenic fungi.

Table 6. In vitro antifungal activity of the S57 strain. Results are indicated as percentage of IMRG. Error corresponds to standard deviation of three independent assays. N.D.: not determined.

\begin{tabular}{cccc}
\hline \multirow{2}{*}{ Fungus } & \multicolumn{3}{c}{ IMRG (\%) } \\
\cline { 2 - 4 } & Standard Conditions & Saline-Boric Conditions & Lluta Irrigation Water \\
\hline B. cinerea & $48.3 \pm 5.8$ & $42.8 \pm 5.3$ & $43.3 \pm 4.4$ \\
F. oxysporum & $23.5 \pm 2.8$ & $26.3 \pm 3.2$ & $22.8 \pm 4.2$ \\
G. candidum & $58.6 \pm 7.0$ & $29.6 \pm 3.6$ & N.D. \\
M. fructicola & $67.2 \pm 8.1$ & $52.3 \pm 6.3$ & N.D. \\
\hline
\end{tabular}

\subsection{Growth Optimization of the S57 Strain in Flask and Bioreactor Conditions}

Three parameters (temperature, $\mathrm{pH}$, and agitation) were modified independently to optimize the bacterial growth of the S57 strain (Table 7). No significant differences were observed in the generational time and the microbial growth rate when incubation temperature was varied from $25^{\circ} \mathrm{C}$ to $35^{\circ} \mathrm{C}$, as is observed in Table $7 ; 35^{\circ} \mathrm{C}$ being the temperature with the highest $\mu\left(2.98 \mathrm{~h}^{-1}\right)$ and the lowest $\mathrm{g}(0.33 \mathrm{~h})$ and it is considered as the optimum growth temperature. A significant decrease in $\mu$ and increase in $g$ were registered at higher temperatures.

Table 7. Optimal conditions for the growth of S57 bacterium. Each optimum parameter was determined by maintaining the other two parameters invariable. Error corresponds to the standard deviation of three independent assays.

\begin{tabular}{ccc}
\hline Parameter & $\mathbf{g} \mathbf{( h )}$ & $\boldsymbol{\mu}\left(\mathbf{h}^{\mathbf{- 1}}\right)$ \\
\hline Temperature $\left({ }^{\circ} \mathrm{C}\right)$ & & \\
25 & $0.35 \pm 0.03$ & $2.85 \pm 0.24$ \\
30 & $0.34 \pm 0.04$ & $2.89 \pm 0.34$ \\
35 & $0.33 \pm 0.02$ & $2.98 \pm 0.18$ \\
40 & $1.26 \pm 0.22$ & $0.79 \pm 0.14$ \\
\hline $\mathrm{pH}$ & & \\
5.0 & $0.48 \pm 0.04$ & $2.07 \pm 0.17$ \\
5.5 & $0.30 \pm 0.02$ & $3.45 \pm 0.23$ \\
6.0 & $0.30 \pm 0.01$ & $3.32 \pm 0.11$ \\
6.5 & $0.31 \pm 0.03$ & $3.25 \pm 0.31$ \\
7.0 & $0.32 \pm 0.03$ & $3.13 \pm 0.29$ \\
7.5 & $0.31 \pm 0.04$ & $3.25 \pm 0.42$ \\
\hline Agitation $(\mathrm{rpm})$ & & \\
0 & $6.54 \pm 0.50$ & $0.15 \pm 0.01$ \\
50 & $1.89 \pm 0.17$ & $0.53 \pm 0.05$ \\
100 & $0.46 \pm 0.09$ & $2.16 \pm 0.42$ \\
\hline 50 & $0.33 \pm 0.04$ & $3.06 \pm 0.37$ \\
\hline
\end{tabular}

Higher microbial growth rates and lower generational times were determined when the S57 isolate was inoculated in a buffered culture medium in the $\mathrm{pH}$ range from 5.5 to 7.5 (Table 7). When King's medium B was buffered at $\mathrm{pH} 5.0$, a decrease in $\mu\left(2.07 \mathrm{~h}^{-1}\right)$ was observed. The $\mathrm{pH}$ range between 5.5 and 6.0 was considered as optimum $\mathrm{pH}$ for bacterial growth in the bioreactor.

The lowest generational time $(0.33 \mathrm{~h})$ and the highest microbial growth rate $\left(3.06 \mathrm{~h}^{-1}\right)$ were registered when the S57 strain was grown using $150 \mathrm{rpm}$ of agitation (Table 7) and 
this is considered as the optimum agitation speed. Higher $g$ values and lower $\mu$ rates were determined when the agitation speed is reduced.

Optimization in the bioreactor was performed using a two-variables experiment (Table 13), where aeration and impeller speed (agitation) were modified simultaneously to increase the cellular mass of the S57 strain. Optimal temperature and $\mathrm{pH}$ were selected from in flask assays. Two-variables experiment results are shown in Table 8. Higher CFU/mL $\left(2.5 \times 10^{27} \mathrm{CFU} / \mathrm{mL}\right)$ and biomass $(47.1 \mathrm{~g} / \mathrm{L})$ were obtained when experiment number six was carried out ( $0.5 \mathrm{VVM}$ of aeration and $75 \mathrm{rpm}$ of agitation) and its parameters were considered as optimal parameters for the growth of the S57 strain in the bioreactor. However, no bacterial growth was observed when $150 \mathrm{rpm}$ of impeller speed was used after $48 \mathrm{~h}$ post-inoculation (not showed).

Table 8. Optimization of growth of the S57 strain in bioreactor. Error represents standard deviation of the independent assays.

\begin{tabular}{ccc}
\hline Experiment Number & Log $($ CFU/mL) & Biomass $(\mathbf{g} / \mathbf{L})$ \\
\hline 1 & 23.2 & $35.9 \pm 5.40$ \\
2 & 21.3 & $33.0 \pm 6.60$ \\
3 & 19.0 & $29.4 \pm 7.35$ \\
4 & 22.1 & $34.5 \pm 6.90$ \\
5 & 23.9 & $37.1 \pm 4.50$ \\
6 & 27.4 & $47.1 \pm 6.30$ \\
7 & 26.9 & $41.7 \pm 6.30$ \\
\hline
\end{tabular}

2.6. Effect of the Temperature and the Addition of Stabilizing Agents to Formulations of the S57 Strain

Viability of the S57 strain in liquid culture medium in the presence and absence of stabilizing agents carboxymethylcellulose (CMC), cocamidopropyl betaine, Tween 20, and Triton X-100 at $0.1 \%$ final concentration was evaluated for 6 months when a dilution of $\sim 5 \times 10^{9} \mathrm{CFU} / \mathrm{mL}$ was prepared and stored at room temperature and $4{ }^{\circ} \mathrm{C}$ (Figure 2). It was observed that viable bacterial counting decreased over the month for the five formulations stored at room temperature and $4{ }^{\circ} \mathrm{C}$. The formulations reached values of $\sim 1 \times 10^{7} \mathrm{CFU} / \mathrm{mL}$ after one month of storage at room temperature and kept constant for 6 months, except for $0.1 \%$ Triton X-100 for which viability was reduced to $\sim 1 \times 10^{6} \mathrm{CFU} / \mathrm{mL}$ up to the fourth month. After this, the S57 viability was recovered reaching values similar to the other formulations. Similar behavior was observed at $4{ }^{\circ} \mathrm{C}$ where the viable count diminished to values close to $1 \times 10^{7} \mathrm{CFU} / \mathrm{mL}$ after six months of storage, except for $0.1 \%$ cocamidopropyl betaine stored at $4{ }^{\circ} \mathrm{C}$, which possesses the lowest viability after six months $\left(5.73 \times 10^{6} \mathrm{CFU} / \mathrm{mL}\right)$.

Auxin production by the S57 strain was variable according to the formulation employed (Figure 3). The highest values were obtained for formulations containing $0.1 \%$ of Triton X-100 stored at room temperature and $4{ }^{\circ} \mathrm{C}$ for six months and values reached $19.78 \mu \mathrm{g} / \mathrm{mL}$ and $15.31 \mu \mathrm{g} / \mathrm{mL}$, respectively. These results suggest that this formulation produces a biostimulant based on the S57 bacteria and $0.1 \%$ of Triton X-100. Meanwhile, the lowest values were obtained for $0.1 \%$ of CMC after six months of storage in which IAA productions were $1.72 \mu \mathrm{g} / \mathrm{mL}\left(4^{\circ} \mathrm{C}\right)$ and $2.10 \mu \mathrm{g} / \mathrm{mL}$ (room temperature).

Antagonistic activity against $B$. cinerea by the different formulations of the S57 strain was evaluated for six months to determine if this activity could be reduced due to storage (Figure 4). It was possible to observe that four formulations (Control, Tween 20, Triton $\mathrm{X}-100$, and $\mathrm{CMC}$ ) reduced the biocontrol activity against $B$. cinerea considerably during the first month, while cocamidopropyl betaine formulations did not show important losses for this activity. Furthermore, all formulation stored at the two temperatures exhibited a considerable increase in antagonistic activity in vitro and reached values $~ 75 \%$ of mycelial growth inhibition of $B$. cinerea, except for the $0.1 \% \mathrm{CMC}$ formulation stored at room 
temperature in which mycelial growth inhibition reached $\sim 66 \%$. These results reveal that all formulations increased the antagonistic activity of S57 against B. cinerea during storage.

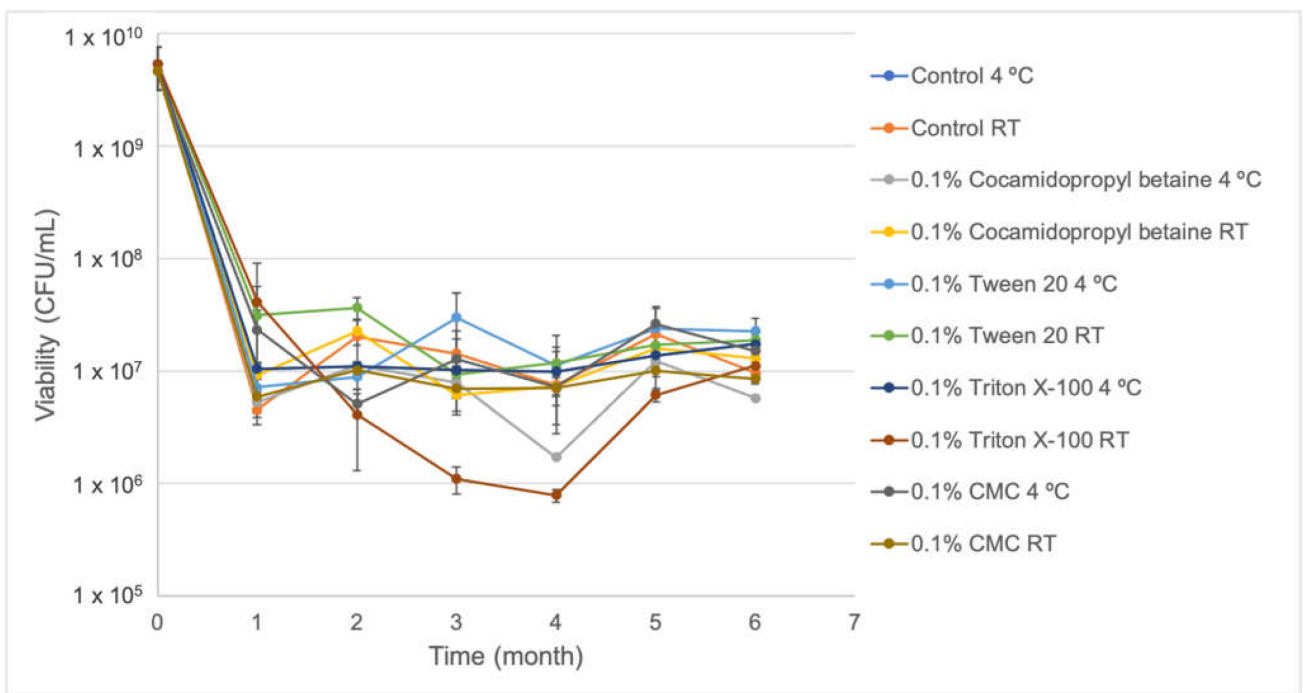

Figure 2. Viability of five formulations of the S57 strain stored at room temperature and $4{ }^{\circ} \mathrm{C}$. Error bars represent the standard deviation of the independent assays.

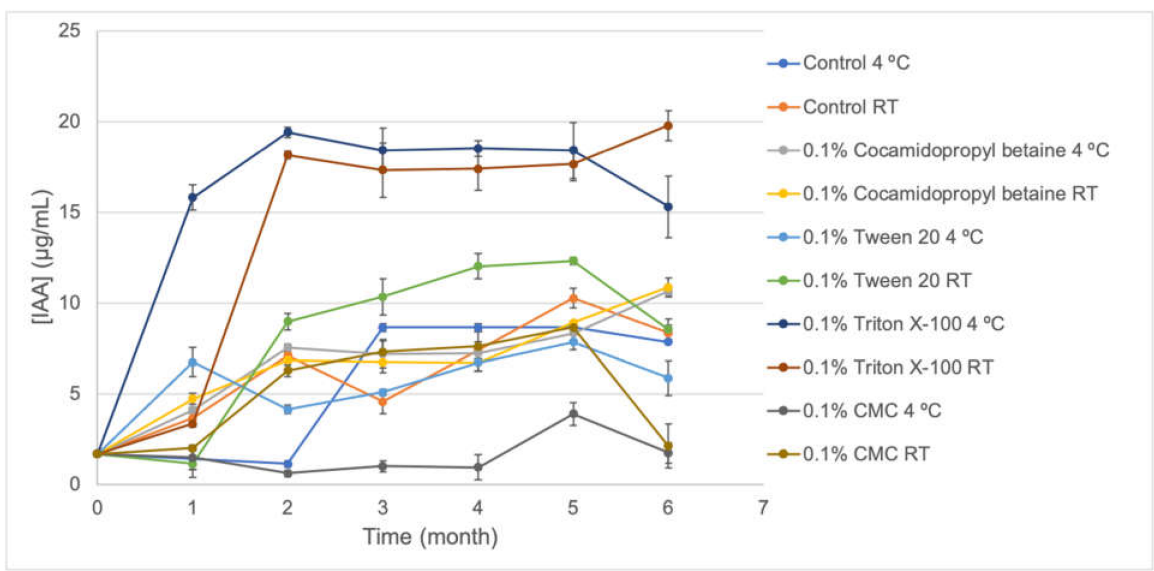

Figure 3. IAA production of five formulations of the S57 strain stored at room temperature and $4{ }^{\circ} \mathrm{C}$. Error bars represent the standard deviation of the independent assays.

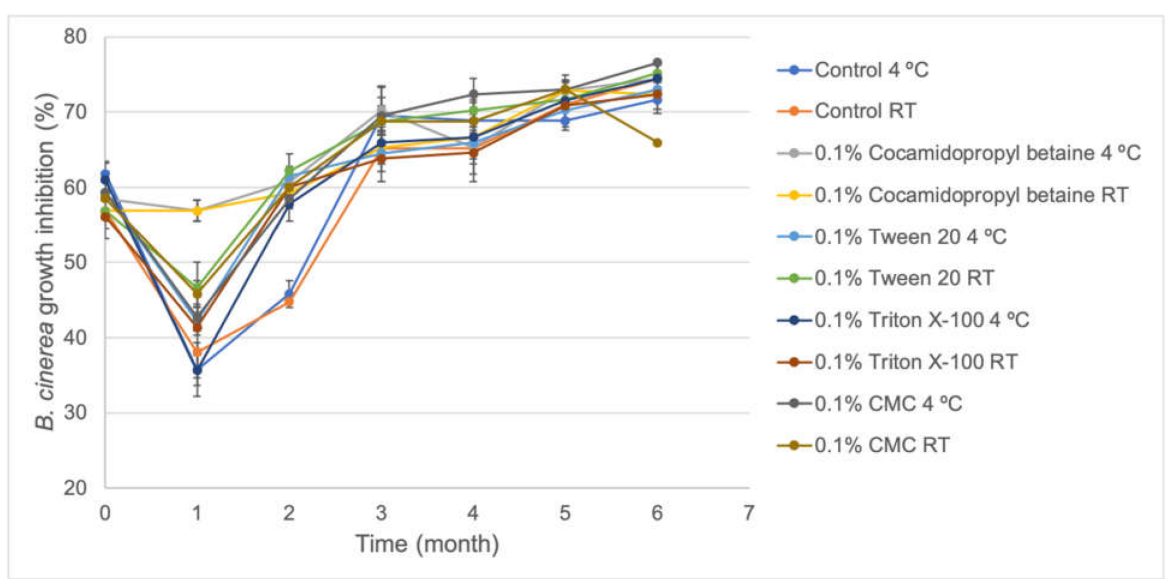

Figure 4. Antagonistic activity against $B$. cinerea of five formulations of the S57 strain stored at room temperature and $4{ }^{\circ} \mathrm{C}$. Error bars represent the standard deviation of the independent assays. 


\subsection{PGP Activity of the S57 Strain in Micro-Tom Tomato Plants}

In order to test the plant-growth promotion ability of the S57 strain, Micro-Tom tomato plants were inoculated with fresh $1 \times 10^{8} \mathrm{CFU}$ of this bacterium (S57 treatment) and compared with uninoculated plants or control conditions (Table 9 and Figure 5). A higher development in the aerial part of the plant was measured when Micro-Tom tomato plants were treated with the S57 bacterium and an increase of 2.27-fold was observed in the wet weight and 1.33-fold in stem length compared to uninoculated plants. However, no significant differences were observed in the dry and wet weight of treated roots compared to the control.

Table 9. Effect of the application of the S57 strain in the Micro-Tom tomato plants growth. Error represents standard deviation of the five independent assays.

\begin{tabular}{cccc}
\hline & Control & S57 Treatment & Fold \\
\hline Stem length $(\mathrm{cm})$ & $11.8 \pm 1.40$ & $15.7 \pm 1.10$ & 1.33 \\
Root wet weight $(\mathrm{g})$ & $2.3 \pm 0.40$ & $2.7 \pm 0.50$ & 1.18 \\
Root dry weight $(\mathrm{g})$ & $0.18 \pm 0.04$ & $0.18 \pm 0.04$ & 1.00 \\
Aerial wet weight $(\mathrm{g})$ & $2.36 \pm 1.00$ & $5.35 \pm 1.00$ & 2.27 \\
Aerial dry weight $(\mathrm{g})$ & $0.57 \pm 0.10$ & $0.83 \pm 0.10$ & 1.46 \\
\hline
\end{tabular}

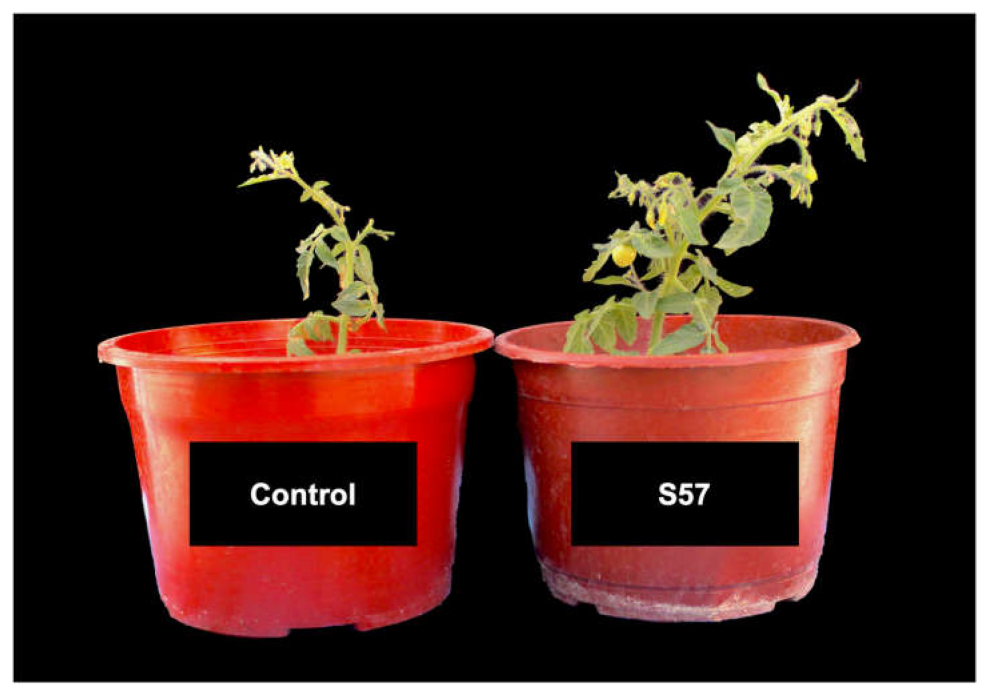

Figure 5. Representative image of Micro-Tom tomato plant growth treated with the S57 strain in comparison to untreated plants (control). Plants were irrigated with saline-boric water from Azapa Valley and grown in perlite as substrate.

\subsection{Biocontrol Aactivity of S57 Strain in Plants Against Phytopathogenic Fungi}

Table 10 shows the height of bell pepper plants after 30 days of cultivation. Considering the conditions of the evaluation, plants exposed to B. cinerea and F. oxysporum, statistical analysis showed significant differences between the treatments $(p \leq 0.05$; capital and lowercase letters, respectively), which allowed two level grouping: Control and Serenade (Gold Standard, GS) as statistical group one; and S57 as a statistical group two. For bell peppers plants in the presence of $B$. cinerea, the S57 treatment was higher than control and the GS; meanwhile, in the presence of F. oxysporum, S57 and GS treatments were equal.

Fresh weight was determined from the third leaf in bell pepper plants cv. Almuden (Table 11) after 30 days of cultivation in pots to determine the effect of the S57 treatment in the plant growth. For this evaluation, a random design was considered with four replicates; this allowed the definition of two statical groups: GS with lower weight; and S57 with the same weight as the control and grouped in a second superior level. 
Table 10. Height of bell pepper plants cv. Almuden treated with S57 strain in comparison to control and GS treatments. Error represents the standard deviation of the three independent assays. The same letters represent statistical equality (Tukey test, $p \leq 0.05$ ).

\begin{tabular}{ccc}
\hline Treatment & B. cinerea & F. oxysporum \\
\hline S57 & $26.0 \pm 1.0^{\mathrm{b}}$ & $26.0 \pm 1.0^{\mathrm{A}}$ \\
Serenade & $21.7 \pm 1.5^{\mathrm{a}}$ & $26.0 \pm 1.0^{\mathrm{A}}$ \\
Control & $23.0 \pm 1.0^{\mathrm{a}}$ & $27.7 \pm 2.1^{\mathrm{B}}$ \\
\hline
\end{tabular}

Table 11. Fresh weight of the third leaf of pepper plants cv. Almuden treated with the S57 strain in comparison to control and GS treatments. Error represents the standard deviation of the four independent assays. The same letters represent statistical equality (Tukey test, $p \leq 0.05$ ).

\begin{tabular}{cc}
\hline Treatment & Fresh Weight $(g)$ \\
\hline S57 & $1.68 \pm 0.3^{\mathrm{b}}$ \\
Serenade & $1.34 \pm 0.3^{\mathrm{a}}$ \\
Control & $1.66 \pm 0.5^{\mathrm{b}}$ \\
\hline
\end{tabular}

When evaluating the effect of the treatments on B. cinerea damage (Figure 6), no significant differences were detected between the treatments even though they effectively exert a mitigating effect equal to the GS. Despite this, the infection was limited in all treatments and the foliar development of the treatments was adequate according to the plant phenological state (Figure 5).

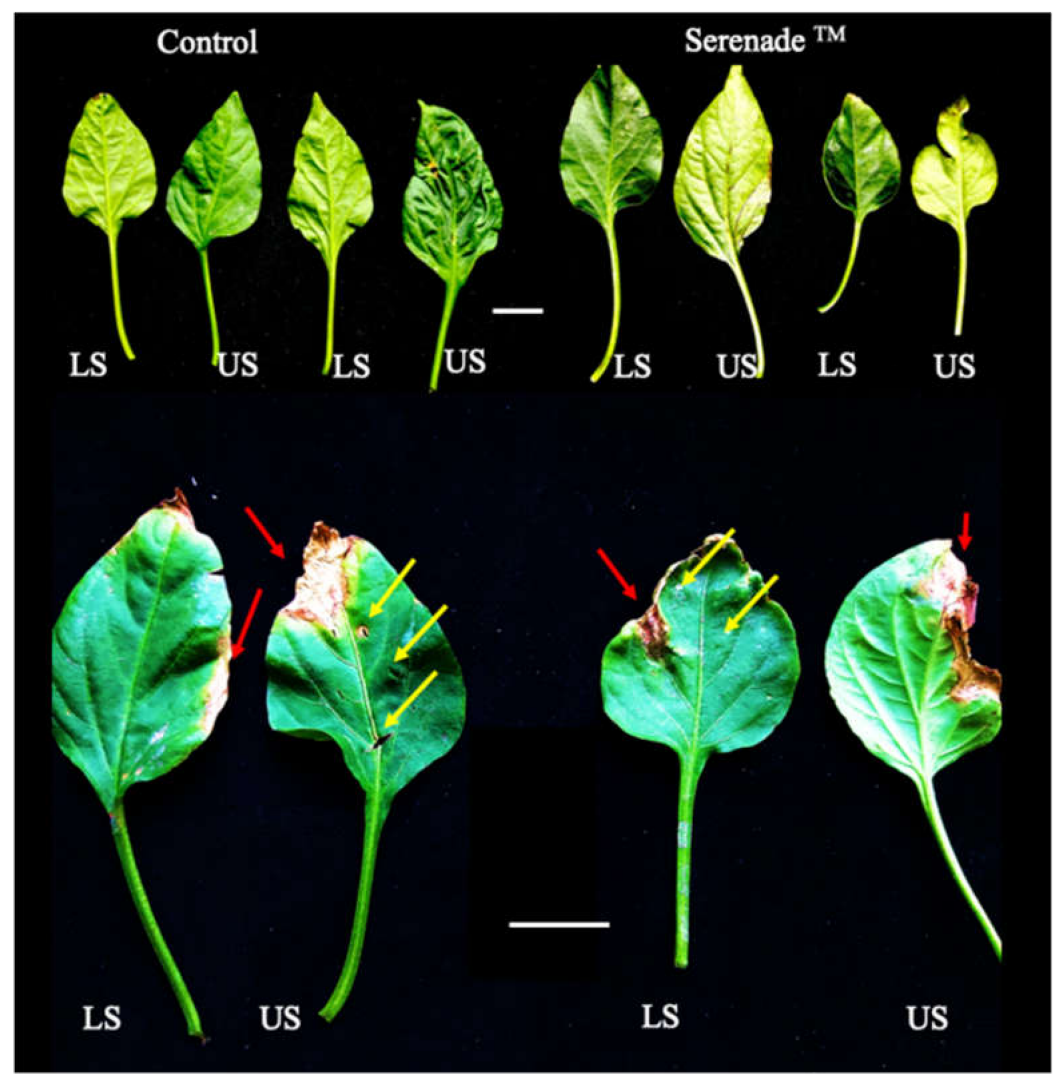

Figure 6. Development of the third leaf in bell pepper plants cv. Almuden after undergoing 5 treatments. Red arrows indicate B. cinerea damage points. Yellow arrows indicate inoculation wounds without infection. Abbreviations: LS: lower side; US: upper side. White scale bars represent $2 \mathrm{~cm}$. 


\subsection{Nematicide Activity of S57 Strain in Plants Against Meloidogyne Incognita}

As expected, the non-inoculated tomato plants cv. Poncho Negro did not present galls, while the plants with $M$. incognita inoculum (without any controller) presented 2.428 galls $/ 100 \mathrm{~g}$ of roots. The plants treated with fluopyram presented 2 galls $/ 100 \mathrm{~g}$ of roots (Table 12) and presented data that validates the extensive use of this nematicide in commercial productions. From the treatment with the S57 strain, it was possible to count 689 galls $/ 100 \mathrm{~g}$ of roots. This information allows consideration that the S57 bacterium exerts a moderate effect on the root-knot formation of $M$. incognita in tomato plants. By using $4-5$ separate applications every 5 to 10 days, the inhibitory effect on the formation of galls could probably be higher.

Table 12. The number of galls of $M$. incognita per $100 \mathrm{~g}$ of roots of tomato plants cv. Poncho Negro. Error represents standard deviation of the four independent assays. The same letters represent the statistical equality (Tukey test, $p \leq 0.05$ ).

\begin{tabular}{cc}
\hline Treatment & $\mathbf{N}^{\circ}$ Galls \\
\hline Control without inoculate & $0 \pm 0^{\mathrm{a}}$ \\
Control without controller & $2428 \pm 109^{\mathrm{b}}$ \\
S57 & $689 \pm 83^{\mathrm{c}}$ \\
Fluopyram & $2 \pm 2^{\mathrm{a}}$ \\
\hline
\end{tabular}

\section{Discussion}

Arid and semi-arid environments are widely distributed worldwide, occupying between $30 \%$ to $40 \%$ of the global terrestrial surface. Under these conditions, soil fertility is constrained by different environmental factors, including wide thermal amplitudes, low water availability, reduced bioavailable nitrogen and phosphorous, decreased waterholding capacity, and extreme $\mathrm{pH}$ values, low soil organic matter (ranging from $0.1 \%$ to $3 \%$ ) among other specific limitations [17]. Socoroma soils have been maintained using ancestral agricultural practices and pesticides-free soil managements, which was confirmed by pesticides residues analysis for 330 types of agrochemicals (not showed). However, several plant limiting factors were detected (Table 1), including increased values in electrical conductivity higher than $80 \mathrm{dS} / \mathrm{cm}$ with a reduced quantity of $\mathrm{Na}$ (less than $0.33 \mathrm{cmol} / \mathrm{kg}$ ), suggesting non-sodium highly saline soils. Salinity affects the productivity and yields of crops by reducing plant biomass, leaf area, and growth, which can be explained by the increase in soil osmotic pressure. The interference in the nutrient and water uptake; diminished $\mathrm{CO}_{2}$ availability with reduced photosynthetic pigments content that directly affects photosynthesis; and salt accumulation in roots that promotes the development of osmotic stress and disrupt cell ion homeostasis by inhibiting the uptake of essential elements $\left(\mathrm{K}^{+}\right.$, $\mathrm{Ca}^{2+}$, and $\mathrm{NO}_{3}{ }^{-}$) and favors the accumulation of $\mathrm{Na}^{+}$and $\mathrm{Cl}^{-}$and promoting specific ion toxicities, which causes the inhibition of photosynthesis and protein synthesis, inactivate enzymes, and damages chloroplasts and other organelles [18].

Furthermore, high aluminum content was detected in Socoroma soils, which can exert a toxic effect on plants and diminishes their growth. As the concentration of aluminum increases, the soil $\mathrm{pH}$ decreases and the toxic effect of this metal appears, which have an important growth-limiting factor in acid soils below $\mathrm{pH} 5.0$ (as it was observed in S1 and $\mathrm{S} 2$ soil samples, Table 1) where $\mathrm{Al}^{3+}$ ions predominate. Under these conditions, aluminum interferes with the elongation of root tips and lateral roots. Cell walls become more rigid by the formation of cross-linking pectins; inhibits DNA replication through the increase in DNA rigidity; bonds to phosphorous forming less available and insoluble compounds in soil and on root surfaces and thereby creating phosphorous deficiency; and affects the metabolism, disturbs the essential nutrient uptake and transport, and causes alteration in nutrient balance $[19,20]$.

Plants possess mechanisms to reduce the toxic effect mediated by salinity and aluminum. In addition, a significant contribution to mitigating a variety of abiotic stress is 
carried out by plant-associated microorganisms at the plant phyllosphere, rhizosphere, and endosphere [21]. Several biomolecules are produced by PGPR, which act as plant growth regulators under saline conditions and allows plants to tolerate the adverse environments. Among these, molecules include the production of phytohormones, the enzyme 1-aminocyclopropane-1-carboxylate deaminase (reduces ethylene levels), siderophores, and microbial exopolysaccharides among others [11,21]. Meanwhile, aluminum toxicity can be diminished by plant-associated bacteria through the production of organic acids, such as malic acid, citric acid, oxalic acid, malonic acid, tartaric acid, and salicylic acid, which not only chelates $\mathrm{Al}^{3+}$ but also can bind to phosphorous and reduces the toxic effect of aluminum in roots [22-24]. Panhwar et al. [22] also described that exopolysaccharide production could mitigate the aluminum-induced acidification through the absorption of $\mathrm{H}^{+}$, increasing $\mathrm{pH}$ values at the rhizosphere, and proving a protective layer in the roots, which could chelate metallic ions due to the presence of active functional groups. Aluminum detoxification was described by Mora et al. [25] through the production of siderophores by members of Klebsiella, Stenotrophomonas, Enterobacter, and Serratia genera. Iron and aluminum have a similar ionic radius, suggesting the formation of $\mathrm{Al}^{3+}$-siderophore complexes and reducing the aluminum toxic effects.

Additionally, Farh et al. [26] suggest the activation of aluminum-stress related genes in Arabidopsis thaliana (AtAIP: Al-induced protein gene; AtALS3: Al-sensitive 3 gene; and AtALMT1: Al-activated maleate transporter 1 gene) when plants were treated with PGPR of Pseudomonas, Chryseobacterium, and Burkholderia genera that are isolated from Korean ginseng. The S57 strain has the ability to produce siderophores and IAA to fix elemental nitrogen and to solubilize inorganic phosphate (Table 5); stimulate Micro-Tom tomato growth using irrigation water from Azapa Valley (Table 9 and Figure 5); and can tolerate saline-boric conditions (Table 4); it would be interesting to determine the mechanisms associated to plant-growth promotion for this bacterium and to determine how this strain could increase the plant tolerance to abiotic factors, such as salinity, presence of boron, and aluminum.

The in vitro biocontrol activity of the S57 isolate against phytopathogenic fungi is promising because this property is maintained even under saline-boric conditions (Table 6). Moreover, biocontrol activity against $B$. cinerea was evidenced under the saline-boric conditions of the Azapa Valley using bell pepper plants (Table 10; Figure 6), but no statistical differences relative to control conditions were observed when F. oxysporum was used as phytopathogenic fungus. This difference was expected due to the lower in vitro biocontrol activity against $F$. oxysporum determined by the antagonistic assay (Table 6). Additionally, the S57 strain reduced the number of galls formed by M. incognita under saline-boric conditions and represents an interesting alternative for developing a new bioproduct with nematicide activity. These results show that the S57 bacterium possesses characteristics of an interesting biocontrol agent with antifungal and nematicide activities which require an exhaustive characterization.

The agricultural potential of the S57 strain renders it an excellent candidate for the development of a new biostimulant and biocontrol agent for agriculture in arid and semiarid environments. Thus, it is gaining more importance considering that the increasing worldwide soil salinity process could reach $50 \%$ of arable soils by 2050 [18] and current commercial bioproducts show non-reproducible results when they are applied to crops maintained under these extreme conditions of cultivation [27].

For the development of bioproducts, it is important to generate a highly concentrated microbial culture for the production's success. Several factors are crucial for increasing bacterial cell biomass during the production process, including time-saving and costeffective methods. It is possible to adjust some growth factors, such as $\mathrm{pH}$, temperature, agitation, and incubation time [28], to improve bacterial biomass. For the $\mathrm{S} 57$ strain, $\mathrm{pH}$, temperature, and agitation were performed in a flask to determine optimal parameters for inoculum preparation and bacterial scale-up under bioreactor conditions. This bacterium was able to grow optimally at $35^{\circ} \mathrm{C}$ in a pH range from 5.5 to 6.0 using $150 \mathrm{rpm}$ of agitation 
(Table 7) and producing $\sim 12.0 \mathrm{~g} / \mathrm{L}$ in $48 \mathrm{~h}$, representing a significant increase in biomass in comparison to initial conditions, where less than $1 \mathrm{~g} / \mathrm{L}$ was produced during 1 week under non-optimal conditions (not showed). Further improvements were achieved when the S57 strain was grown in a fermenter using 0.5 VVM of aeration and $75 \mathrm{rpm}$ of impeller agitation (Table 8$)$, reaching $\sim 47.1 \mathrm{~g} / \mathrm{L}$ of biomass $\left(\sim 2.5 \times 10^{27} \mathrm{CFU} / \mathrm{mL}\right)$ in $24 \mathrm{~h}$.

S57 viability showed to be very stable in the absence and presence of stabilizer compounds $(0.1 \%$ cocamidopropyl betaine, CMC, Triton X-100, and Tween 20$)$ after six months stored at $4{ }^{\circ} \mathrm{C}$ and at room temperature (Figure 2), ranging from $\sim 1 \times 10^{6} \mathrm{CFU} / \mathrm{mL}$ to $\sim 1 \times 10^{7} \mathrm{CFU} / \mathrm{mL}$ and increasing their biocontrol activity in vitro against $B$. cinerea (Figure 4) for all formulations. Meanwhile, IAA production (Figure 3) was notoriously increased in $0.1 \%$ Triton X-100, making this formulation a potential biostimulant product. Several formulations based on Pseudomonas bacteria have been reported. For Pseudomonas fluorescens AMB-8 where a notorious decrease in viable cell counting was detected when the bacterium was incubated at room temperature for 6 months without the addition of any protective agent to King's medium B or nutrient broth. The amendment of nutrient broth with $2 \%$ glycerol improved the viability of this strain to $10^{7} \mathrm{CFU} / \mathrm{mL}$ compared to $10^{5} \mathrm{CFU} / \mathrm{mL}$ in non-amended nutrient broth [29]. He et al. [30] also observed an improvement in the viability of Pseudomonas putida RS-198 when bentonite, alginate, CMC, and polyvinyl alcohol were used as stabilizer agents to culture medium after 6 months of incubation. Particularly for the S57 strain, non-notorious improvements in viability were observed when protective agents were added to the bacterial formulation. A bacterium-based bioproduct must be formulated appropriately to guarantee that it will provide all the beneficial traits that it is supposed to afford. The incorporation of stabilizers substances to S57 liquid formulation allowed maintaining higher viable cells and functionally active bacteria during long-term storage. Several protective compounds have been employed to increased bacterial viability during time, including natural polymers (carrageenan, arabic gum, xanthan gum, gelatin, and alginate), synthetic polymers (polyvinyl alcohol and polyvinylpyrrolidone), horticultural oils, glycerol, and mono-saccharides and di-saccharides; all of these must protect the bacterium from abiotic stress generated during storage [31]. It is important to mention that solid formulations (granules and dry and wet powders) could extend the S57 strain stability over time. For example, Pseudomonas tolaasii IEXb maintained its viability after 6 months stored at $4^{\circ} \mathrm{C}$, when it was freeze-dried using whey as the carrier and sodium glutamate as the stabilizer agent; meanwhile, a minor reduction in viable bacterial cells from $10^{9} \mathrm{CFU} / \mathrm{mL}$ to $10^{6} \mathrm{CFU} / \mathrm{mL}$ was observed at room temperature [31]. The salineboric tolerance, PGP traits, and biocontrol activities for the S57 strain are promising and reveal the possibility to develop a new biostimulant and biofungicide that are functional and active under arid and semi-arid conditions. Additionally, the produced biomass of the S57 strain is attractive compared to other bacterial products and allow high quantities of the bacterium to be obtained in a single fermentation step. However, further studies are necessary to improve the viability during storage and to characterize the mechanisms of plant-growth promotion and antifungal biocontrol activity.

\section{Materials and Methods}

\subsection{Sampling and Bacterial Isolation}

Sample collection was performed at three sites in Socoroma, Arica and Parinacota Region, Chile, in 2017 (Table 1). Samples consisting of entire oregano plants were collected aseptically using a metallic shovel disinfected with $70 \%(v / v)$ ethanol and stored in sterilized plastic bags $(17 \times 11$ inch). Soil samples were taken for composition and pesticide residues analysis (Analab, Santiago, Metropolitan Region, Chile). Samples were kept at $4{ }^{\circ} \mathrm{C}$ in a cooler and immediately transported to the laboratory for processing.

The S57 strain was isolated following the procedure described by Muñoz et al. [6] and is part of the plant-associated bacterial culture collection of the Laboratory of Plant Pathology and Bioproducts belonging to the Universidad de Tarapacá. This collection comprises one hundred eighty bacteria, which is functionally characterized for the bacterial 
PGP traits. The S57 isolate was selected from the culture collection due to their promising in vitro PGP activities and obtained using the method described by Yang et al. [32] by cutting oregano roots into small parts and disinfected using 95\% $(v / v)$ ethanol for $2 \mathrm{~min}$, $2 \%(v / v)$ sodium hypochlorite for $2 \mathrm{~min}$, and $70 \%(v / v)$ ethanol for $2 \mathrm{~min}$ followed by two washes of autoclaved distilled water for $2 \mathrm{~min}$ each time. The disinfected portions were placed into plates of King's medium B [33] containing the following (per liter): $20.0 \mathrm{~g}$ peptone, $10.0 \mathrm{~mL}$ glycerol, $1.5 \mathrm{~g} \mathrm{~K}_{2} \mathrm{HPO}_{4}, 1.5 \mathrm{~g} \mathrm{MgSO}_{4} \cdot 7 \mathrm{H}_{2} \mathrm{O}$, and $15.0 \mathrm{~g}$ agar (pH 7.0); and incubated at $25^{\circ} \mathrm{C}$ for 1 week or until microbial growths were observed. Colonies were isolated using serial dilutions on King's B broth and streaking on plates of solid medium. Incubations were performed at room temperature. Isolated colonies were transferred to a liquid medium. These procedures were repeated until a single and homogeneous morphology was observed under the microscope.

The isolated S57 strain was deposited in the Chilean Collection of Microbial Genetics Resources under the accession number RGM2930.

\subsection{Bacterial Identification}

Genomic DNA from selected PGPR was obtained using the DNeasy UltraClean Microbial kit (QIAGEN, Germantown, Maryland, USA) according to the procedure described by the manufacturer. The $16 \mathrm{~S}$ rRNA gene was amplified by PCR using bacteria-specific primers $27 \mathrm{~F}$ and $1492 \mathrm{R}$ [34]. PCR reaction mix and PCR cycles were performed according to the procedure described by Muñoz et al. [6]. Amplification reactions were performed using a VeritiTM 96-well Thermal Cycler (Thermo Fisher Scientific, Waltham, Massachusetts, USA). A band of $\sim 1500 \mathrm{bp}$ was observed after amplification on $1.0 \%(w / v)$ agarose gel prepared in 1X TAE buffer ( $40 \mathrm{mM}$ Tris-acetate, $10 \mathrm{mM}$ EDTA) and visualized under UV light using 1X GelRed (Biotium (San Francisco, LA, USA). The PCR products were sequenced using the primers described above (Macrogen (Seoul, Korea)) and manually edited using the ChromasPro software (http:/ / technelysium.com.au/wp/chromaspro/ accessed on 1 April 2020) to remove low-quality bases. Forward and reverse sequences were assembled using the Megamerger tool (http:/ / www.bioinformatics.nl/cgi-bin/emboss/megamerger accessed on 1 April 2020) to obtain a sequence length of $1448 \mathrm{bp}$. The partial sequence was compared to GenBank using BLAST software [35]. The partial 16S rRNA gene sequence was deposited in the GenBank nucleotide sequences databank under accession number MK883138.

The partial sequence of $16 \mathrm{~S}$ rRNA obtained from the S57 strain and selected sequences belonging to the Pseudomonas genus retrieved from GenBank were aligned using the Clustal $\mathrm{W}$ software [36]. The alignment was manually edited to obtain sequences of similar length. Phylogenetic analysis was carried out using the MEGA7 software [37] and by considering the Aquifex pyrophilus strain Kol5a as the outgroup. The phylogenetic tree was inferred from the multiple sequence alignments by using the Neighbor-Joining method and by using a bootstrap analysis of 1000 replicates to determine the reliabilities of each node.

\subsection{Bacterial Characterization}

The phenotypic characterization of the S57 strain was performed according to the procedure described by Muñoz et al. [38].

Antibiotic susceptibility was carried out using the disk diffusion method according to Simirgiotis et al. [39] by using different antibiotics as observed in Table 3. Two dissimilar quantities of each antibiotic were employed to determine if the S57 strain had differences in its behavior in the susceptibility test. The assay was performed using five independent replicates.

\subsection{Tolerance of the S57 Strain to $\mathrm{NaCl}$ and $\mathrm{H}_{3} \mathrm{BO}_{3}$}

The tolerance of the $\mathrm{S} 57$ strain to $\mathrm{NaCl}$ was determined using King's medium B supplemented with $0-20 \mathrm{~g} / \mathrm{L}$ of $\mathrm{NaCl}$. The tolerance to $\mathrm{H}_{3} \mathrm{BO}_{3}$ was determined using King's medium B amended with 0-100 ppm of $\mathrm{H}_{3} \mathrm{BO}_{3}$. 
A mixture consisting of King's medium B supplemented with $0.86 \mathrm{~g} / \mathrm{L} \mathrm{NaCl}$ and 114 ppm of $\mathrm{H}_{3} \mathrm{BO}_{3}(1 \times)$ was used to emulate the characteristics of the irrigation water of the Lluta River, which is the main source of water for crops in Socoroma [40], and to determine the tolerance of the S57 strain proving that this bacterium can grow under the extreme water conditions of this zone. Furthermore, the medium was amended with a higher concentration up to $10 \times$ the irrigation water of the Lluta River.

Bacterial growth was monitored each day during one weak of incubation through the measurement of $\mathrm{OD}_{600}$ using a spectrophotometer. Bacterial growth was registered as ++ for abundant growth, which is similar to control condition (absent of $\mathrm{NaCl}$ and $\mathrm{H}_{3} \mathrm{BO}_{3}$ ); + for poor growth; and - for no growth. All assays were carried out using three independent replicates.

\subsection{In Vitro PGP Traits}

Inorganic phosphate solubilization was detected in Pikovskaya (PVK) solid medium according to the method described by Pikovskaya [41]. The appearance of a clearing zone around the bacterial colony after incubation is indicative of phosphate solubilization.

Nitrogen fixation was determined using $\mathrm{NFb}$ semisolid medium using the procedure described by Rodríguez [42] in which nitrogen fixation is defined by the formation of a sub-superficial whitish 'veil-like' pellicle after incubation.

The production of IAA was quantified using the colorimetric Salkowski's method [43]. Bacterial supernatant was mixed with Salkowski's reagent $\left(0.5 \mathrm{M} \mathrm{FeCl}_{3}\right.$ in $\left.35 \% \mathrm{HClO}_{4}\right)$ in the ratio of 1:2 (supernatant: Salkowski's reagent) in the dark at room temperature. A calibration curve was adjusted using an IAA standard using the concentration range $0-50 \mu \mathrm{g} / \mathrm{mL}$ and the absorbance at $530 \mathrm{~nm}$ was measured using a T60 UV/VIS spectrophotometer (PG Instruments Limited).

Siderophores production was quantified by the Chrome Azurol S (CAS) method described by Schwynand and Neilands [44], where a ratio of 1:1 of supernatant: CAS reagent was employed and the absorbance at $630 \mathrm{~nm}$ was registered using a UV/VIS spectrophotometer after $20 \mathrm{~min}$ of incubation. Siderophore production was in percent siderophore unit (psu) according to the following formula:

$$
\mathrm{psu}=(\mathrm{Ar}-\mathrm{As}) \times 100 / \mathrm{Ar}
$$

where $\mathrm{Ar}$ is the absorbance of the reference (CAS solution and un-inoculated medium) and As is the absorbance of the supernatant of the S57 strain.

All experiments for in vitro PGP traits were carried out using three independent replicates.

\subsection{Antifungal Activity}

In vitro growth inhibition of phytopathogenic fungi was determined through a dual culture assay performed in potato dextrose agar (PDA) plates by using the phytopathogenic fungi B. cinerea, F. oxysporum, G. candidum, and M. fructicola inoculated at the center of each plate and aliquots of the S57 strain were inoculated surrounding the fungus according to the method described by Sepúlveda-Chavera et al. [45]. As controls, plates with only the fungus in the center were used. The inhibition of the mycelial radial growth (IMRG) of the fungus will be calculated using the following equation:

$$
\mathrm{IMRG}=[(\mathrm{C}-\mathrm{T}) / \mathrm{C}] \times 100
$$

where $\mathrm{C}$ is the growth area of the fungus in the control plate and $\mathrm{T}$ is the fungal growth area using the treatment.

Moreover, the same experiment was performed using PDA plates amended with $10 \mathrm{~g} / \mathrm{L} \mathrm{NaCl}$ and $110 \mathrm{ppm} \mathrm{H}_{3} \mathrm{BO}_{3}$ (saline-boric conditions) to determine if biocontrol activity against phytopathogenic fungi is maintained under saline-boric conditions. Furthermore, dual culture assays against B. cinerea and F. oxysporum (common phytopathogenic 
fungi in the Arica and Parinacota Region) were also performed using PDA plates prepared with twice-autoclaved irrigation water from the Lluta River instead of distilled water.

All antifungal assays were carried out using three independent replicates.

\subsection{S57 Culture Optimization}

A growth curve was performed by taking $1 \mathrm{~mL}$ aliquots each $1 \mathrm{~h}$ during $48 \mathrm{~h}$ from the culture medium inoculated with the S57 strain. Bacterial growth was monitored by the increase in $\mathrm{OD}_{600}$ using a spectrophotometer and viable count was monitored busing serial dilutions on a solid medium.

Flask-experiments were conducted until the stationary phase using a final volume of $200 \mathrm{~mL}$ of bacterial culture. This strategy was used to characterize and model the behavior of the $\mathrm{S} 57$ strain by defining the variables of the process (agitation, $\mathrm{pH}$, and temperature) to promote bacterial growth in the flask. The effect of each parameter was recorded by obtaining growth curves and calculating generational time $(\mathrm{g})$ and microbial growth rate $(\mu)$. Two variables were maintained constant to determine each optimum parameter.

The S57 strain was inoculated in King's medium B and the temperature was maintained in a shaker incubator to determine the temperature effect. The range of temperature to be assayed was $25-40^{\circ} \mathrm{C}$.

The S57 strain was inoculated in King's medium B and pH was buffered to 5.0-6.0 using $50 \mathrm{mM}$ MES and 6.5-7.5 using $50 \mathrm{mM}$ HEPES in order to determine the $\mathrm{pH}$ effect and adjusted to their respective values using $\mathrm{NaOH}$ or $\mathrm{HCl}$.

The effect of agitation was determined in a shaker incubator at room temperature by using different agitation speeds between 0-150 rpm.

The S57 strain culture was scaled up in a one-liter bioreactor $\left(\right.$ BioFlo $^{\circledR} /$ CelliGen $^{\circledR}$ 115 fermenter) under optimal flask-conditions. Optimization in the bioreactor was performed by using the design of a two-variables experiment where aeration and agitation were modified simultaneously according to Table 13. The experimental temperature was maintained at $35^{\circ} \mathrm{C}$ and $\mathrm{pH}$ was controlled to 5.5-6.0 using $5 \%(w / v) \mathrm{H}_{3} \mathrm{PO}_{4}$ and $5 \%(w / v)$ $\mathrm{NaOH}$. Biomass and viable count were determined to select optimal growth conditions of the S57 strain in the bioreactor.

Table 13. Experimental design to optimize S57 strain culture conditions in bioreactor.

\begin{tabular}{ccc}
\hline Experiment Number & Aeration (VVM) & Agitation (rpm) \\
\hline 1 & 0.5 & 100 \\
2 & 1.0 & 100 \\
3 & 1.5 & 100 \\
4 & 0.5 & 50 \\
5 & 1.5 & 50 \\
6 & 0.5 & 75 \\
7 & 1.5 & 75 \\
8 & 0.5 & 150 \\
9 & 1.0 & 150 \\
10 & 1.5 & 150 \\
\hline
\end{tabular}

For viable counts, samples of $1 \mathrm{~mL}$ were taken after $24 \mathrm{~h}$ of incubation and serial dilutions were prepared in sterile King's medium B. Each dilution was inoculated in a solid medium and colonies counting was performed after incubation to determine colonyforming units per $\mathrm{mL}(\mathrm{CFU} / \mathrm{mL})$.

Furthermore, bacterial viability was determined once a month using dilutions of the S57 strain to $\sim 5 \times 10^{9} \mathrm{CFU} / \mathrm{mL}$ and stored at room temperature and $4{ }^{\circ} \mathrm{C}$ for six months. For this purpose, four formulations were generated using the stabilizing agents carboxymethylcellulose (CMC), cocamidopropyl betaine, Tween 20, and Triton X-100 at $0.1 \%$ final concentration.

Samples of $1 \mathrm{~mL}$ were taken once a month and serial dilutions in sterile King's medium B were performed. Each dilution was inoculated in a solid medium and colony 
counting was determined after incubation as described above. Experiments were executed using three replicates. Moreover, in vitro antifungal activities against $B$. cinerea and auxin production were monitored monthly according to the procedure described above.

\subsection{PGP Activity of the Strain S57 in Micro-Tom Tomato Plants}

PGP activity was also evaluated in Micro-Tom tomato plants (Tomato Genetics Resource Center, University of California Davis). Micro-Tom tomato seeds were disinfected using $95 \%(v / v)$ ethanol for $2 \mathrm{~min}, 2 \%(v / v)$ sodium hypochlorite for $2 \mathrm{~min}$, and $70 \%(v / v)$ ethanol for 2 min followed by two washes with sterile distilled water for 2 min each time. Seeds were germinated in a sterile dark wet chamber at $25^{\circ} \mathrm{C}$ for ten days. After their germination, Micro-Tom seedlings were transferred to pots containing twice autoclaved perlite as the only substrate and were kept in a greenhouse. Plants were treated once a week for a month using $1 \times 10^{8} \mathrm{CFU}$ of the S57 strain by the application of the bacterium at the stem's base. The fresh inoculum was prepared and diluted in sterile water. Micro-Tom tomato plants treated only with sterile King's medium B were used as a control. Plants were watered daily with irrigation water from the Azapa Valley. After 4 weeks of inoculation, the Micro-Tom plants were removed from the substrate and washed and the length of the stem, wet weight, and dry weight of the roots and the aerial parts were measured separately. Experiments were carried out using five independent replicates.

\subsection{Biocontrol Activity of the S57 Strain in Planta Against Phytopathogenic Fungi}

In order to determine the biocontroller effect of the S57 bacterium, a planta assay was designed in pots with plants of bell pepper cv. Almuden (Syngenta ${ }^{\circledR}$ ). The plants were obtained from a commercial nursery and transplanted when they had the first true expanded leaf (two weeks of germination). The experimental design corresponded to a completely randomized design with uniform management. The application of bacteria suspended in water was the only source of variation. A positive control treatment (Gold Standard, GS) corresponding to Bacillus subtilis (Serenade ${ }^{\circledR}$-Syngenta) was considered. Plants that were not inoculated and treated only with water were used as a negative control. The plants were grown in commercial peat as substrate and fertilized after the first week of transplantation and watered daily. The experimental design considered three replicates. After 10 days of transplantation, two phytopathogenic fungi were incorporated: B. cinerea and F. oxysporum. For the inoculation of bell pepper plants, $2 \mathrm{~mL}$ of a suspension $\left(10^{6} \mathrm{CFU} / \mathrm{mL}\right)$ of $B$. cinerea conidia was applied to each plant. F. oxysporum was inoculated in conidial suspension $\left(10^{6} \mathrm{CFU} / \mathrm{mL}\right)$ by applying $2 \mathrm{~mL}$ per plant at a location close to the neck of the plants. Each fungus was applied in independent pots.

The S57 strain and the GS were applied three times: 5, 15, and 25 days after transplantation. The development of foliar symptoms and plant height were evaluated. For each application, an independent suspension of each bacterium was prepared in a liquid proteose peptone medium and it was cultivated at $35^{\circ} \mathrm{C}$ for $48 \mathrm{~h}$ using $150 \mathrm{rpm}$ of shaking (obtaining a concentration of $1 \times 10^{9} \mathrm{CFU} / \mathrm{mL}$ ). For the application in plants, $1 \mathrm{~mL}$ of the medium with bacterial growth was taken and it was suspended at a rate of $1 \mathrm{~mL}$ of broth in $1 \mathrm{~L}$ of sterile distilled water. Three $\mathrm{mL}$ of bacterial suspension were applied to each plant using a manual spray pump.

\subsection{Nematicide Activity of the S57 Strain in Planta \\ 4.10.1. Nematode Isolation}

The nematode $M$. incognita was obtained from an axenic population maintained in tomato plants cv. Poncho Negro. The nematode collection was performed by the method described by Hussey and Barker [46] and modified by Bonetti and Ferraz [47]. The roots of tomato plants infested by the nematode were gently washed to release the adhered soil and macerated in the presence of $0.5 \% \mathrm{NaClO}$. The nematode suspension was filtered using a 500-mesh sieve to retain the eggs; the total count of the eggs was conducted in a Peters chamber using a stereomicroscope. The suspension was calibrated to $5000 \mathrm{eggs} / \mathrm{mL}$. 


\subsubsection{In Planta Nematicide Assay}

In order to determine the nematicide effect of the S57 strain, tomato plants cv. Poncho Negro were transplanted to $3 \mathrm{~L}$ pots using a mixture of peat: perlite $(2: 1)$ as soil substrate. Four treatments were considered for the assay: tomato plants without $M$. incognita eggs (Control without inoculating), tomato plants inoculated only with M. incognita eggs (Control without controller), tomato plants inoculated with M. incognita eggs and treated with fluopyram at commercial dosses $(3 \mathrm{mg} / \mathrm{plant}$ diluted in irrigation water) (Chemical control), and tomato plants inoculated with M. incognita eggs and treated with the S57 strain. After two days of transplantation, one $\mathrm{mL}$ of $M$. incognita eggs ( $5000 \mathrm{eggs} / \mathrm{mL})$ was inoculated to each respective plant in the roots. For the S57 strain, one $\mathrm{mL}$ of bacterial suspension $\left(1 \times 10^{6} \mathrm{CFU} / \mathrm{mL}\right)$ was added twice with ten days of separation. Tomato plants were cultivated for 35 days. The experiment represented a completely randomized design with 4 replicates. After cultivation, $100 \mathrm{~g}$ of roots were obtained and the number of galls was determined for each treatment.

\section{Conclusions}

The S57 strain is an endophytic bacterium associated with oregano roots from Socoroma (the Atacama Desert) and it is a member of the Pseudomonas genus that is closely related to P. lini. This bacterium has PGP traits, including the ability to fix nitrogen, solubilize phosphorous, produce IAA and siderophores, and promote the growth of aerial parts of Micro-Tom tomato plants. Furthermore, the S57 strain can tolerate saline boric conditions. It can inhibit the mycelial growth of phytopathogenic fungi in vitro, even in the presence of $\mathrm{NaCl}$ and $\mathrm{H}_{3} \mathrm{BO}_{3}$ which renders it a good candidate for the development of a new bioproduct functional and active under desertic conditions. Moreover, the S57 bacterium possesses biocontroller activity in planta against the fungus $B$. cinerea and the nematode $M$. incognita under saline-boric conditions. This bacterium can be produced in high quantities and remains viable and functionally active after 6 months of storage. However, it is necessary to improve its viability over time and further characterize the mechanisms associated with PGP and biocontrol activities.

\section{Patents}

Two patent applications were requested to INAPI under the accession number 202000346 and 202000348.

Author Contributions: All authors contributed to the study conception and design. Material preparation, sampling, and experimental procedures were performed by P.M.T., M.A.M., S.C., N.H., W.H.-M., D.C. and G.F.S.C. Data analyses were executed by P.M.T. and G.F.S.C. The first draft of the manuscript was written by P.M.T. and G.F.S.C. All authors have read and agreed to the published version of the manuscript.

Funding: This work was supported by the FIC-CORFO Project 13CEI2-21852 and the execution of the Project Co-execution Agreement between the Universidad de Tarapacá and the University of California Davis Chile ('Decreto Exento' Nº0.451/2018).

Institutional Review Board Statement: Not applicable.

Informed Consent Statement: Not applicable.

Data Availability Statement: Data is contained within the article.

Acknowledgments: This manuscript was edited by Ricardo Reyes from the Editing Office of Universidad de Tarapacá. Additionally, we would like to acknowledge Elías Fernando Marín Fuentes (R.I.P.), who was an important member of the Faculty of Agronomic Sciences of Universidad de Tarapacá and a key collaborator of our work. Moreover, we appreciate the collaboration of the Socoroma community for allowing us to execute this study.

Conflicts of Interest: The authors declare no conflict of interest. 


\section{References}

1. Rodríguez, A.; Tapia, A.; Albornoz, C. Susceptibilidad de movimientos en masa en el valle de Socoroma, Precordillera andina de Arica y Parinacota. Diálogo Andino 2014, 44, 25-39. [CrossRef]

2. Espinosa, S. Variabilidad Climática y Adaptación Social en Socoroma y Caquena: Una Propuesta de Educación Ambiental. Bachelor's Thesis, University of Chile, Santiago, Chile, 2013.

3. INAPI. Orégano de la Precordillera de of Putre. Available online: https://www.inapi.cl/sello-de-origen/productos-registradosy-en-proceso/norte-grande (accessed on 2 April 2021).

4. Berg, G.; Grube, M.; Schloter, M.; Smalla, K. Unraveling the plant microbiome: Looking back and future perspectives. Front. Microbiol. 2014, 5, 148. [CrossRef] [PubMed]

5. El Amrani, A.; Dumas, A.; Wick, L.; Yergeau, E.; Berthomé, R. “Omics” insights into PAH degradation toward improved green remediation biotechnologies. Environ. Sci. Technol. 2015, 49, 1128-11291. [CrossRef] [PubMed]

6. Muñoz, P.; Arismendi, M.; Cárdenas, S.; Cifuentes, D.; Venegas, F.; Sepúlveda-Chavera, G. Diversity of culturable bacteria isolated from ancestral crops of Arica and Parinacota Region, Atacama Desert. Antonie Leeuwenhoek 2020, 113, 2123-2137. [CrossRef] [PubMed]

7. Cornejo, L. Recursos hídricos y desarrollo socioeconómico en zonas áridas: Importancia y perspectivas de nuevas tecnologías aplicadas al tratamiento de aguas naturales y/o residuales. Ingeniare Rev. Chilena Ing. 2009, 17, 285-287. [CrossRef]

8. Yadav, A. Beneficial role of extremophilic microbes for plant health and soil fertility. J. Agric. Sci. Bot 2017, 1, 30-31. [CrossRef]

9. Majeed, A.; Abbasi, M.; Hameed, S.; Imram, A.; Rahim, N. Isolation and characterization of plant growth-promoting rhizobacteria from wheat rhizosphere and their effect on plant growth promotion. Front. Microbiol. 2015, 6, 198. [CrossRef]

10. Marques, A.; Pires, C.; Moreira, H.; Rangel, A.; Castro, P. Assessment of the plant growth promotion abilities of six bacterial isolates using Zea mays as indicator plant. Soil Biol. Biochem. 2010, 42, 1229-1235. [CrossRef]

11. Qin, Y.; Druzhinina, I.; Pan, X.; Yuan, Z. Microbially mediated plant salt tolerance and microbiome-based solutions for saline agriculture. Biotech. Adv. 2016, 34, 1245-1259. [CrossRef]

12. Rilling, J.; Acuña, J.; Sadowky, M.; Jorquera, M. Putative nitrogen-fixing bacteria associated with the rhizosphere and root endosphere of wheat plants grown in an andisol from southern Chile. Front. Microbiol. 2018, 9, 2710. [CrossRef]

13. Crowley, D. Microbial siderophores in the plant rhizosphere. In Iron Nutrition in Plants and Rhizospheric Microorganisms, 1st ed.; Barton, L., Abadia, J., Eds.; Springer: Dordrecht, The Netherlands, 2006; pp. 169-198.

14. Kalayu, G. Phosphate solubilizing microorganisms: Promising approach as biofertilizers. Int J. Agron. 2019, $2019,4917256$. [CrossRef]

15. Islam, S.; Akanda, A.; Prova, A.; Islam, M.d.T.; Hossain, M.d.M. Isolation and identification of plant growth promoting rhizobacteria from cucumber rhizosphere and their effect on plant growth promotion and disease suppression. Front. Microbiol. 2016, 6, 1360. [CrossRef]

16. Jha, C.; Saraf, F. Plant growth promoting Rhizobacteria (PGPR): A review. J. Agric. Res. Dev. 2015, 5, 108-119.

17. Thomas, R.; El-Dessougi, H.; Tubeileh, A. Soil system management under arid and semi-arid conditions. In Biological Approaches to Sustainable Soil Systems, 1st ed.; Uphoff, N., Ball, A., Fernandes, E., Herren, H., Husson, O., Laing, M., Palm, C., et al., Eds.; CRC Press: New York, NY, USA, 2006.

18. Almeida, R.; Serralheiro, P. Soil salinity: Effect on vegetable crop growth. Management practices to prevent and mitigate soil salinization. Horticulturae 2017, 3, 30.

19. Bojórquez-Quintal, E.; Escalante-Magaña, C.; Echevarría-Machado, I.; Martínez-Estévez, M. Aluminum, a friend or foe of higher plants in acid soils. Front. Plant. Sci. 2017, 8, 1767. [CrossRef]

20. Rout, G.; Samantaray, S.; Das, P. Aluminium toxicity in plants: A review. Agronomie 2001, 21, 3-21. [CrossRef]

21. Sorty, A.; Bitla, U.; Meena, K.; Singh, N. Role of microorganisms in alleviating abiotic stresses. In Microorganisms for Green Revolution, 1st ed.; Panpatte, D., Jhala, Y., Shelat, H., Vyas, R., Eds.; Springer: Singapore, 2018.

22. Panhwar, Q.; Naher, U.; Radziah, O.; Shamshuddin, J.; Razi, I. Eliminating aluminum toxicity in an acid sulfate soil for rice cultivation using plant growth promoting bacteria. Molecules 2015, 20, 3628-3646. [CrossRef]

23. Pineros, M.; Kochian, L. Overview of the structure-function relations underlying functionality of ALMT and MATE-type transporters involved in the organic acid release $\mathrm{Al}$ tolerance response. In Proceedings of the 7th International Symposium on Plant-Soil Interactions at Low pH; Liao, H., Yan, X., Kochian, L., Eds.; South China University of Technology Press: Guangzhou, China, 2009; pp. 55-56.

24. Yang, L.; Qi, Y.; Jiang, H.; Chen, L. Roles of organic acid anion secretion in aluminium tolerance of higher plants. Biomed. Res. Int. 2013, 2013, 173682. [CrossRef]

25. Mora, M.; Demanet, R.; Acuña, J.; Viscardi, S.; Rengel, Z.; Jorquera, M.; Duran, P. Aluminum-tolerant bacteria improve the plant growth and phosphorus content in ryegrass grown in a volcanic soil amended with cattle dung manure. Appl. Soil Ecol. 2017, 115, 19-26. [CrossRef]

26. Farh, M.; Kim, Y.; Sukweenadhi, J.; Singh, P.; Yang, D. Aluminium resistant, plant growth promoting bacteria induce overexpression of aluminium stress related genes in Arabidopsis thaliana and increase the ginseng tolerance against aluminium stress. Microbiol. Res. 2017, 200, 45-52. [CrossRef]

27. Salvatierra-Martínez, R.; Sepúlveda-Chavera, G.; Huanca-Mamani, W.; Rodríguez-Molina, M. Native strains of Trichoderma from northern Chile: Adaptive tolerance in boric saline soils. Interciencia 2015, 40, 263-269. 
28. Ren, H.; Zentek, J.; Vahjen, W. Optimization of production parameters for probiotic Lactobacillus strains as feed additive. Molecules 2019, 24, 3286. [CrossRef]

29. Anith, K.; Vaishakhi, A.; Viswanathan, A.; Varkey, S.; Aswini, S. Population dynamics and efficiency of coconut water based liquid formulation of Pseudomonas fluorescens AMB-8. J. Trop. Agric. 2016, 54, 184-189.

30. He, Y.; Peng, Y.; Wu, Z.; Han, Y.; Dang, Y. Survivability of Pseudomonas putida RS-198 in liquid formulations and evaluation its growth-promoting abilities on cotton. J. Anim Plant. Sci. 2015, 25, 180-189.

31. Lobo, C.; Juárez, S.; Viruel, E.; Ferrero, M.; Lucca, M. Development of low-cost formulation of plant growth-promoting bacteria to be used as inoculants in beneficial agricultural technologies. Microbiol. Res. 2019, 219, 12-25. [CrossRef]

32. Yan, X.; Wang, Z.; Mei, Y.; Wang, L.; Wang, X.; Xu, Q.; Peng, S.; Zhou, Y.; Wei, C. Isolation, diversity, and growth-promoting activities of endophytic bacteria from tea cultivars of Zijuan and Yunkang-10. Front. Microbiol. 2018, 9, 1848. [CrossRef]

33. King, E.; Ward, M.; Raney, D. Two simple media for the demonstration of pyocyanin and fluorescin. J. Lab. Clin. Med. 1954, 44, 301-307. [PubMed]

34. Frank, J.; Reich, C.; Sharma, S.; Weisbaum, J.; Wilson, B.; Olsen, G. Critical evaluation of two primers commonly used for amplification of bacterial 16S rRNA genes. Appl. Environ. Microbiol. 2008, 74, 2461-2470. [CrossRef] [PubMed]

35. Altschul, S.; Gish, W.; Miller, W.; Myers, E.; Lipman, D. Basic local alignment search tool. J. Mol. Biol. 1990, $215,403-410$. [CrossRef]

36. Larkin, M.; Blackshields, G.; Brown, N.; Chenna, R.; McGettigan, P.; McWilliam, H.; Valentin, F.; Wallace, I.M.; Wilm, A.; Lopez, R.; et al. Clustal W and Clustal X version 2.0. Bioinformatics 2007, 23, 2947-2948. [CrossRef]

37. Kumar, S.; Stecher, G.; Tamura, K. MEGA7: Molecular Evolutionary Genetics Analysis version 7.0 for bigger datasets. Mol. Biol. Evol. 2016, 33, 1870-1874. [CrossRef]

38. Muñoz, P.; Márquez, S.; González-Nilo, F.; Márquez-Miranda, V.; Blamey, J. Structure and application of antifreeze proteins from Antarctic bacteria. Microb. Cell Fact 2017, 16, 138-151. [CrossRef]

39. Simirgiotis, M.; Burton, D.; Parra, F.; López, J.; Muñoz, P.; Escobar, H.; Parra, C. Antioxidant and antibacterial capacities of Origanum vulgare L. essential oil from the arid Andean Region of Chile and its chemical characterization by GC-MS. Metabolites 2020, 10, 0414. [CrossRef]

40. Torres, A.; Acevedo, E. The salinity problem of the water and soil resources in Lluta and Azapa Valleys in northern Chile. Idesia 2008, 26, 31-44.

41. Pikovskaya, R. Mobilization of phosphorus in soil in connection with the vital activity of some microbial species. Microbiology $1948,17,362-370$.

42. Rodríguez, E. Improved medium for isolation of Azospirillum spp. Appl. Environ. Microbiol. 1982, 44, $990-991$.

43. Ehmann, A. The Van Urk-Salkowski reagent-a sensitive and specific chromogenic reagent for silica gel thin-layer chromatographic detection and identification of indole derivatives. J. Chromatog. 1977, 132, 267-276. [CrossRef]

44. Schwynand, B.; Neilands, J. Universal chemical assay for the detection and determination of siderophores. Anal. Biochem. 1987, 160, 47-56. [CrossRef]

45. Sepúlveda-Chavera, G.; Macuer, M.; Muñoz, P. Endospore-forming bacteria present in a commercial stabilized poultry manure determines the Fusarium biocontrol and the tomato growth promotion. Agronomy 2020, 10, 1636. [CrossRef]

46. Hussey, R.; Barker, K. Comparison of methods for collecting inocula of Meloidogyne spp., including a new technique. Plant. Dis. Rep. 1973, 57, 1025-1028.

47. Bonetti, J.; Ferraz, S. Modificações do método de Hussey \& Barker para extração de ovos de Meloidogyne exigua em raízes de cafeeiro. Fitopatol. Bras. 1981, 6, 553. 